\title{
FAILURE OF PHYSICAL VAPOUR DEPOSITION COATING ZIRCONIUM NITRIDE ON THE PUNCH OF CLINCHING TOOL
}

\author{
Miroslav DŽUPON*, L'uboš KAŠČÁK**, Dušan NÉMETH*, Réne KUBíK** \\ *Institute of Materials Research, Slovak Academy of Sciences, Watsonova 47, Košice, Slovakia \\ ${ }^{*}$ Technical University of Košice, Faculty of Mechanical Engineering, Mäsiarska 74, Košice, Slovakia \\ mdzupon@imr.saske, lubos.kascak@tuke.sk, dnemeth@imr.saske.sk, rene.kubik@tuke.sk
}

received 10 November 2015, revised 22 May 2017, accepted 25 May 2017

\begin{abstract}
A tool with a punch of $\varnothing 5 \mathrm{~mm}$ and a die with a specially formed circular cavity and an annular gap was used for mechanical joining of thin hot-dip galvanized steel sheets. The active parts of punch and die were covered by PVD coating of ZrN type with LARC technology. The punches and the dies were tested in a complex tool by joining thin hot-dip galvanized steel sheets with the pressing force of 7,000 N. Decohesion of coating with width of $100-200 \mu \mathrm{m}$ was observed in the perimeter of cylindrical part of $ø 5 \times 4 \mathrm{~mm}$ in the in edge of punch radius $R=0.5 \mathrm{~mm}$ with deposited $\mathrm{ZrN}$ coating after the creation of 150 mechanical joints. The decohesion of PVD coating occurred mainly in the surroundings of the radius $R=0.5 \mathrm{~mm}$ on the front plane of $\varnothing 15 \mathrm{~mm}$ part.
\end{abstract}

Key words: Clinching, PVD Coating, FEM

\section{INTRODUCTION}

The automotive industry is currently working to accommodate the conflicting requirements of environmental legislation as well as customer demands for better performance and more features of luxury and safety by combining various materials (Kaščák et al., 2015). It results in combining drawing grade galvanized steel sheets, high-strength galvanized steel sheets, even aluminium alloys, magnesium alloys, copper alloys or using a multimaterial mix, such as a combination of steel aluminium alloy, steel and magnesium alloys and steel and polymer materials (Chen et al., 2016; Jiang et al., 2015; Lambiase and Ilio, 2015; He et al., 2015). Some of these materials are difficult or even impossible to join with conventional resistance spot welding, therefore considerable efforts have gone into developing new joining technologies suitable for joining these materials (He et al., 2015). In engineering design, the use of laser welding and brazing, friction stir welding, mechanical joining, adhesive bonding and some hybrid processes are the most progressive joining technologies. The most utilized methods of mechanical joining are self-piercing riveting (He et al., 2015), clinchriveting (Kaščák et al., 2013) and clinching (Mucha et al., 2011).

Clinching is a joining method in which sheet metal parts are deformed locally - by creating a mechanical interlock, without the use of any additional elements such as screws or rivets (Mucha et al., 2011, 2013; Kaščák et al., 2015). The blanks are plastically deformed and the shape of the tools remains theoretically unchanged during the clinching process. The joints are made by a plastic deformation of the materials; thus sheet predrilling is not required, which leads to a significant reduction in the joining time. After the joint has been made, there is no need for repainting the sheets or performing stress relieving treatments (Lambiase and llio, 2015). The main geometry of forming tools includes: punch diameter, die diameter, depth of the die, radius of punch and die, angle of inclination of the punch and die. These dimensions influ- ence the proper joint formation and the strength of joint (Witkowski, 2015; Mucha and Witkowski, 2014; Lambiase and llio, 2016).

The high-strength steel sheets have a different hardening system during forming in comparison with low carbon steel sheets. The utilization of high-strength steels leads to higher requirements on the tool's active parts and significantly increases tool wear. The intensity of wear on the active parts of the forming tool can be affected, in terms of material, by proper material choice, its optimal heat treatment or chemical and heat treatment and surface treatment. Physical Vapour Deposition (PVD) technology is a currently used method of surface treatment. The basic properties of PVD coating include adhesion, hardness, thickness and roughness (Pulker et al., 1981; Chalker et al., 1991; Rickerby, 1991). Adhesion is defined as the work necessary to separate the coating-substrate interface (Pulker et al., 1981). The adhesion between coating and substrate is one of the basic criteria for the evaluation of the system suitability for further use. In practice, scratch test is the most frequently used method for measuring the adhesion, i.e. bonding strength between coating and substrate. Adhesive properties of PVD coating are evaluated by morphology of coating failure after the scratch test, from the record of acoustic emission signal $A E$, friction coefficient $\mu$ as a function of increasing of force and critical force in which PVD coating is perforated until the substrate appears (ISO 20502(E), 2005; Renzelii et al., 2016). The use of the scratch test and X-ray diffraction showed that the level of residual stress in coating increases with increased roughness of the surface on which the coating is deposited (Attar and Johannesson, 1996). The experimental studies confirmed, that the advanced calculation techniques, based on the finite element method (FEM), can be used in surface engineering as tools for predicting coating properties (Wang et al., 2012; Śliwa).

The research focused on the identification of the cause of $\mathrm{ZrN}$ coating failure in exposed parts of the punch and the die in mechanical joining of hot-dip galvanized sheets. 


\section{EXPERIMENTAL PROCEDURE}

The tool with punch of $\varnothing 5 \mathrm{~mm}$ and die with a special formed circular cavity and annular gap was used for mechanical joining of thin hot-dip galvanized steel sheets (Mucha et al., 2011, 2013; Kaščák et al., 2015). The active parts of punch and die were covered by PVD coating, type ZrN with LARC (Lateral Rotating Arc - Cathodes) technology. Parameters of the coating deposition were as follows: Bias-160 V, ARC Zr-180 A, pressure - 0.008 mbar, temperature $430{ }^{\circ} \mathrm{C}$. The punches and the dies were tested in a complex tool by joining thin hot-dip galvanized steel sheets with the pressing force of $7000 \mathrm{~N}$ (Figs. 1 and 2).

The experimental work focused on the identification of wear mechanisms of the punch in clinching the thin hot-dip galvanized steel sheets. The tools were made of steel of grade 1.3343 (according to standard DIN: S6-5-2) with the following chemical composition measured by mobile spectrometer Belec Compact Port: C- $0.92 \%$, Si-0.31\%, Mn-0.33\%, P-0.019\%, S-0.005\%, Cr$3.88 \%, \mathrm{Mo}-4.76 \%, \mathrm{~V}-1.85 \%, \mathrm{~W}-6.36 \%$. The punch and the die, as the active parts of the joining tool, were heat-treated by vacuum hardening, tempered three times to the final hardness of $55-56$ $\mathrm{HRC}$. The temperatures of tempering were higher than temperature of deposition of PVD coatings.

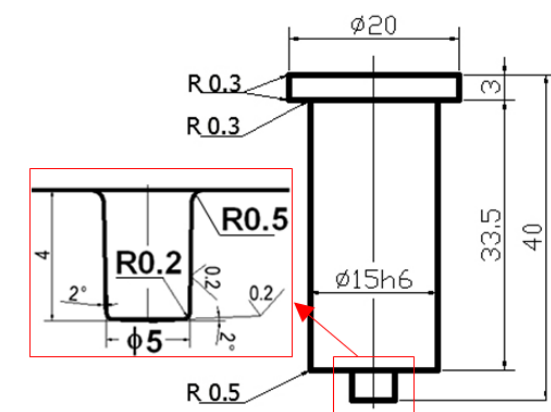

Fig. 1. Punch

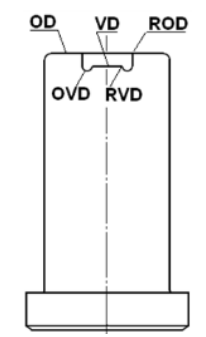

Fig. 2. Die

The surface of the tools was prepared on the grinding machine on the final roughness of less than $\mathrm{Ra} 0.2$. The tools were covered by $\mathrm{ZrN}$ coating. With each group of the tools, the test

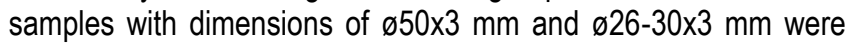
prepared with the same technology of heat treatment, mechanical treatment and coating deposition.

GD-OES (Glow discharge optical emission spectroscopy) method was used for analysis of PVD coatings and their chemical composition. The results of the measurements were recorded as tabular values and deep level concentration profiles, which allowed graphical documentation of the changes in the concentration at maximum depth of $0.1 \mathrm{~mm}$. All the values provide relevant information necessary to identify materials and surface processes.
The chemical composition of coatings measured by GD-OES method was compared with available reference standards.

Phase composition of PVD coatings was determined by the method of oblique incidence ( $\mathrm{GI}$ - grazing incidence) of X-ray. All entries of $\mathrm{GI} X$-ray qualitative phase analysis of the PVD coating were measured at an angle of $2^{\circ}$ of the impact, in the range $20^{\circ}$ to $100^{\circ}$. Figures were created in the EVA evaluation software.

The PVD coating thickness was measured on each sample by Calotest method. The values of microindentation hardness of all PVD coatings deposited on the test samples were determined by microindentation tester TTX-NHT S/N with Berkovich diamond indenter at maximum load of $60.00 \mathrm{mN}$ in sinusoidal mode (sinusoidal frequency $15.0 \mathrm{~Hz}$, sinusoidal amplitude $6.00 \mathrm{mN}$ ) and hold time of $10.0 \mathrm{~s}$ in maximum force.

Friction and wear parameters were measured using a CSM $\mathrm{HT}$ tribometer. All experiments were performed at a temperature of $20 \pm 2{ }^{\circ} \mathrm{C}$. Each sample was measured three times. The beads were made of steel grade $\mathrm{Cr} 100$. Relative speed was $10 \mathrm{~mm} / \mathrm{s}, 20$ $\mathrm{mm} / \mathrm{s}, 100 \mathrm{~mm} / \mathrm{s}$ and $200 \mathrm{~mm} / \mathrm{s}$, normal load was: $2,4,5 \mathrm{~N}$.

The optical method of confocal microscopy and optical interferometry in the phase shift regime (phase shift interference PSI) with vertical resolution of PSI $<0.02 \mathrm{~mm}$, control length of $636 \mu \mathrm{m}$ were used for measuring the surface microgeometry.

Surface parameters were determined according to ISO 4287: $\mathrm{Ra}$ - mean arithmetic deviation; Rz - maximum profile height; $\mathrm{Rq}$ mean square deviation of the profile, and according to ISO 25178 $\mathrm{Sa}$ - surface heights arithmetic average; $\mathrm{Sq}$ - the second central moment of the measured heights of the surface, which provides information on the dispersion of surface heights around the test area of Sa value; Sp - maximum peak height; Sv - maximum pit height; $\mathrm{Sz}$ - the sum of the maximum peak height and minimum depth in a defined area (maximum height).

The surface topography of all tools was observed by scanning electron microscope (SEM) JEOL JSM-7000F with autoemission nozzle and Vega3 Tescan.

The mathematical modelling with finite element method (FEM) was used in the research. The modelling was performed with the commercial software ANSYS v15.0.

\section{RESULTS AND DISCUSSION}

The average thickness of $\mathrm{ZrN}$ coating $2 \mu \mathrm{m}$ was specified by Calotest method. The average values of microindentation hardness HIT measured on PVD coatings were $29 \mathrm{GPa}$. The chemical composition of ZrN coating on the tested samples covered concurrently with relevant group of tools was specified by GD-OES method. The depth-concentration profiles of $\mathrm{Zr}, \mathrm{Ti}, \mathrm{N}$ elements to depth of $5 \mu \mathrm{m}$ were obtained from the measurements.

The measurements outcomes were tabular values and depth concentration profiles of the elements $\mathrm{Zr}, \mathrm{Ti}, \mathrm{N}$, which graphically documented changes in concentration to a depth of $5 \mu \mathrm{m}$. In the ZrN coating, titanium was present in one third of the coating's thickness and on the border between the PVD coating and the surface of the instrument. The titanium present at the interface of the substrate material and the PVD coating is a part of TiN intermediate surface layer. The purpose of this layer is to increase the adhesion of PVD coating (Fig. 3).

ZrN coating phase composition as determined by the oblique incidence ( $\mathrm{GI}$ - grazing incidence) X-ray - only phases of FCC type were present everywhere, therefore diffraction indices were not marked (Fig. 4). 


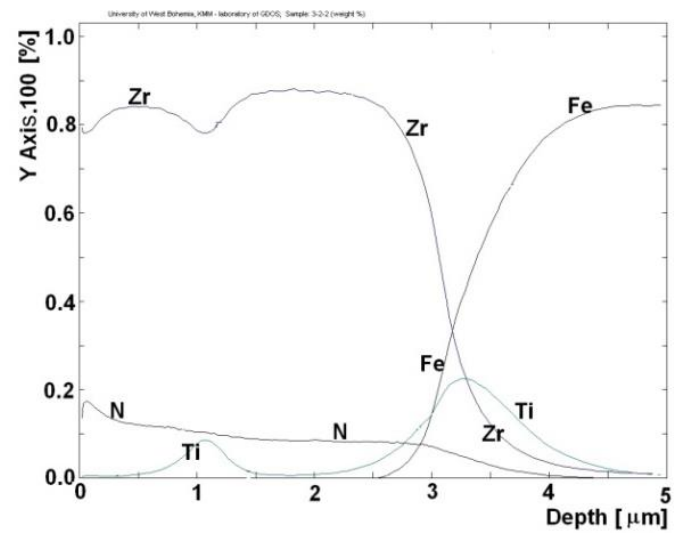

Fig. 3. GD-OES. ZrN coating, substrate $1.3343,55 \mathrm{HRc}$

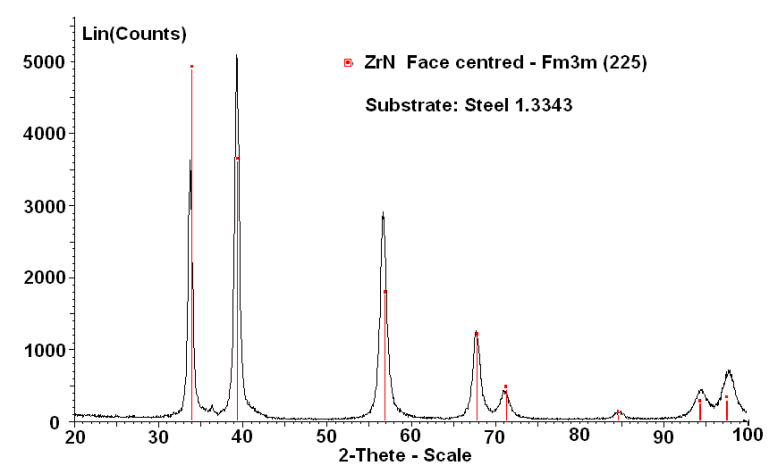

Fig. 4. GI qualitative $\mathrm{X}$-ray analysis

The ZrN coatings contained phase ZrN - FCC - Fm3m (225) with lattice parameters $a=0.45886 \pm 0.00003 \mathrm{~nm}$ and crystal size $9.7 \pm 0.2 \mathrm{~nm}$ to $9.8 \pm 0.3 \mathrm{~nm}$; these values were measured on samples prepared at different times to verify the stability of the coating process.

The roughness of $\mathrm{ZrN}$ coatings deposited on the machineground tool surface depended on the direction of grinding. The $\mathrm{Ra}$ values measured perpendicularly to the grinding direction were almost 1.6 times higher than that of Ra measured in the direction of grinding (Tab. 1).

Tab.1. Microgeometry parameters of $\mathrm{ZrN}$ coating surface $[\mu \mathrm{m}]$

\begin{tabular}{|c|c|c|c|c|c|c|c|}
\hline \multicolumn{5}{|c|}{ ISO 25178} & \multicolumn{3}{|c|}{ ISO 4287} \\
\hline $\mathrm{Sq}$ & $S p$ & Sv & Sz & $\mathrm{Sa}$ & $\begin{array}{l}\text { Ra- } \\
\text { long }\end{array}$ & $\begin{array}{c}\text { Ra- } \\
\text { trans. }\end{array}$ & $\mathrm{Sa}$ \\
\hline 0.47 & 3.89 & 8.86 & 12.75 & 0.37 & 0.18 & 0.3 & 0.35 \\
\hline \multicolumn{8}{|c|}{$\begin{array}{l}\text { Long.- surface parameter measured in the direction of grinding } \\
\text { Trans.- surface parameters measured perpendicularly to the grinding } \\
\text { direction }\end{array}$} \\
\hline
\end{tabular}

The Sp, Sv and Sz parameters contained information about the extreme values of the height parameters of the $\mathrm{ZrN}$ surface coatings. These values are subject to random appearance of isolated extremes in the test area. Commonly used parameter for evaluating surface microgeometry of the test area is aritmetic average Sa. It is a parameter which provides the best statistical characteristics of the actual surface by means of experimental surface height measurements. The arithmetic mean of heights determined by Sa parameter the was almost the same for rough- ness measurement procedures according to ISO 4278 and ISO 25178.

Standard test for PVD coatings is the Pi-on Disc test. Values of the average friction coefficient $\mu$-mean of steel balls and $\mathrm{ZrN}$ coating range from 0.594 to 0.627 and showed no change at changing the normal force value (Tab. 2).

Tab.2. ZrN coating Pin-on-Disc test

\begin{tabular}{|c|c|c|c|c|c|c|c|}
\hline $\begin{array}{c}\boldsymbol{\mu} \text {-start } \\
{[-]}\end{array}$ & $\begin{array}{c}\boldsymbol{\mu} \text {-min } \\
{[-]}\end{array}$ & $\begin{array}{c}\boldsymbol{\mu} \text {-max } \\
{[-]}\end{array}$ & $\begin{array}{c}\boldsymbol{\mu} \text {-mean } \\
{[-]}\end{array}$ & $\begin{array}{c}\boldsymbol{\mu} \text {-Std. } \\
\text { dev. }\end{array}$ & $\begin{array}{c}\mathbf{F} \\
{[\mathbf{N}]}\end{array}$ & $\begin{array}{c}\mathbf{v} \\
{[\mathbf{c m} / \mathbf{s}]}\end{array}$ & $\begin{array}{c}\text { Distance } \\
{[\mathbf{m}]}\end{array}$ \\
\hline 0.221 & 0.221 & 0.675 & 0.627 & 0.060 & 2.0 & 10.0 & 200 \\
\hline 0.169 & 0.169 & 0.726 & 0.594 & 0.049 & 4.0 & 10.0 & 200 \\
\hline 0.152 & 0.152 & 0.816 & 0.597 & 0.052 & 5.0 & 10.0 & 200 \\
\hline
\end{tabular}

The surface morphology of all ZrN coatings after deposition on the punches and the dies was observed by methods of scanning electron microscopy (Fig. 5).

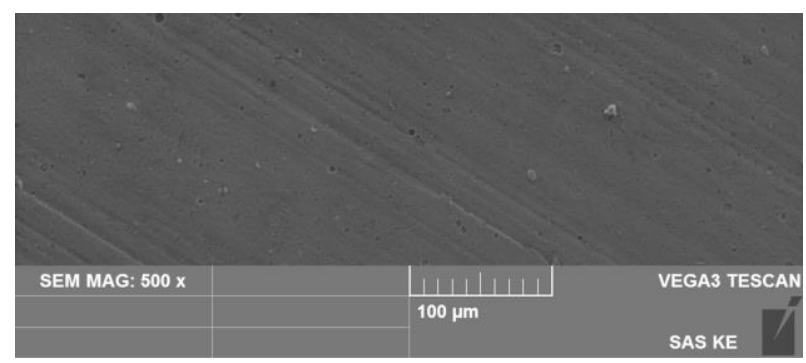

Fig. 5. ZrN coating after deposition SEM

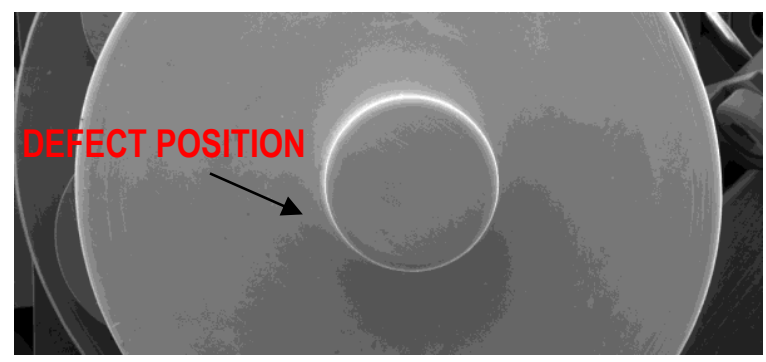

Fig. 6. Defect position in the edge of R0.5

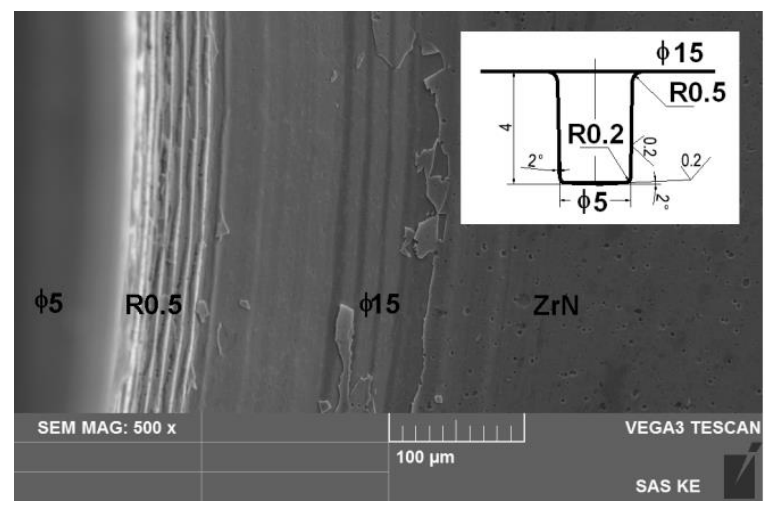

Fig. 7. Decohesion of $\mathrm{ZrN}$ coating in the edge of $\mathrm{R} 0.5$

The surface of $\mathrm{ZrN}$ coating was inspected in the areas of $\varnothing 5$ $\mathrm{mm}, \mathrm{R} 0.2$ and R0.5 of the coated punches (Fig.6). During the clinching process, defects in $\mathrm{ZrN}$ coating on the punch and the die occurred after creation of 150 clinched joints. Decohesion of 
coating with width of $100-200 \mu \mathrm{m}$ in the entire perimeter of the cylindrical part of $\varnothing 5 \times 4 \mathrm{~mm}$ was observed in the in edge of punch radius $\mathrm{R}=0.5 \mathrm{~mm}$ with deposited $\mathrm{ZrN}$. The coating decohesion was mainly situated in surroundings of $\mathrm{R} 0.5$ radius on the front plane of cylindrical part $\varnothing 5 \mathrm{~mm}$ (Fig. 7). In the edge of $\mathrm{R} 0.2$ radius, the coating was intact and the surface morphology corresponded to the surface state after coating deposition (Fig. 7).

Alloying elements of the punch material and $\mathrm{ZrN}$ coating were detected by qualitative EDX microanalysis in the edge of R0.5. The intensity of titanium line was almost the same in the edge of defect and in the intact area of coating. The decohesion was observed in PVD coating (Fig. 8).

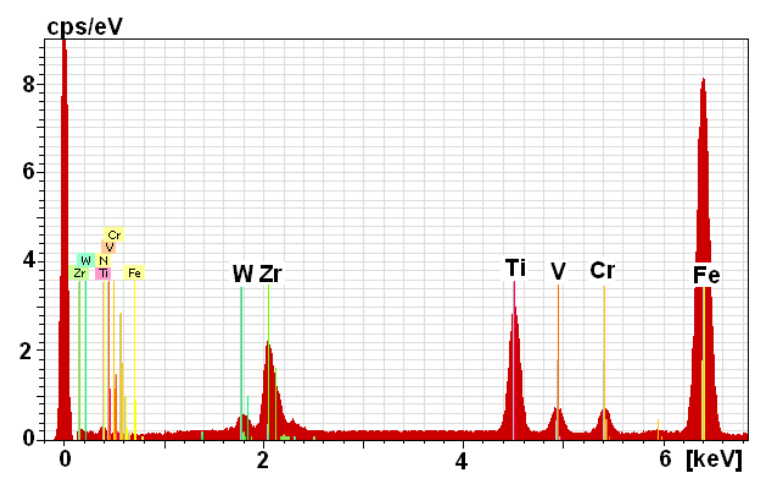

Fig. 8. EDX microanalysis in the edge of R0.5

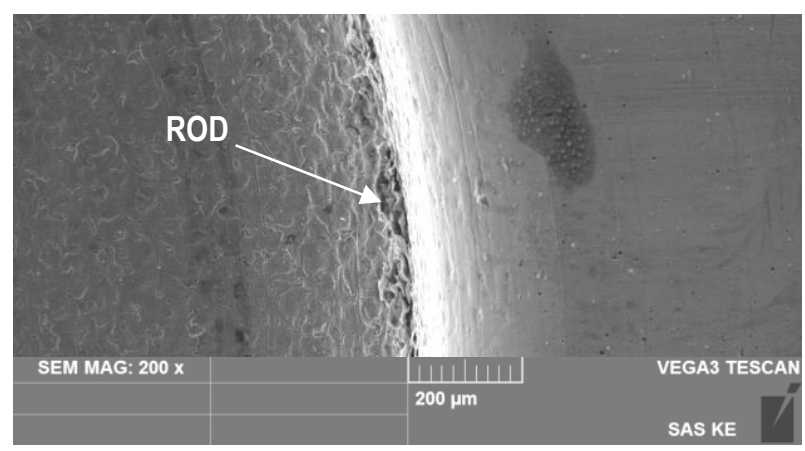

Fig. 9. Die - defect in the radius surrounding the cavity of shaped surface ROD

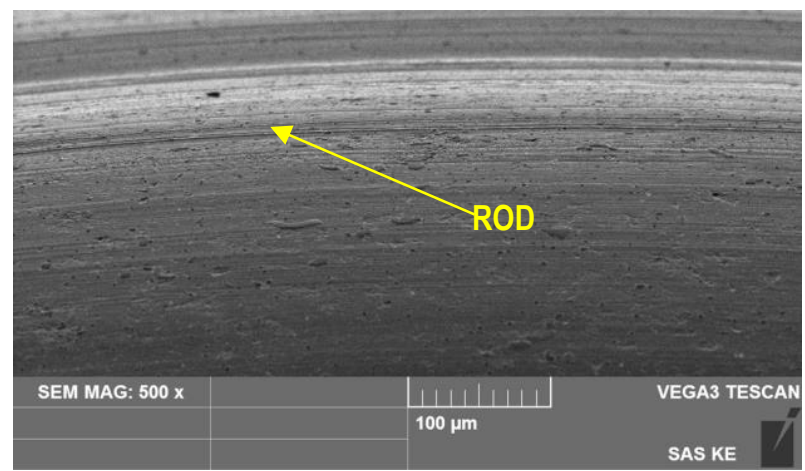

Fig. 10. Die - radius of surrounding of cavity of shaped surface - ROD, after deposition of ZrN coating

There was a low probability of contamination of R0.5 edge with iron from clinched steel sheets, since the joined steel sheets were hot-dip galvanized. Zinc was not detected in the edge of R0.5 by qualitative EDX microanalysis.
The integrity and the morphology of $\mathrm{ZrN}$ coating was observed in the places of shaped surface (Fig. 2): OD - surrounding of cavity of shaped surface, VD - top of cavity of shaped surface, ROD - radius of surrounding of cavity of shaped surface, OVD surrounding of top of cavity of shaped surface, RVD - radius of top of cavity of shaped surface. A partial peel-off of ZrN coating was observed in the ROD (radius of surrounding of cavity of shaped surface) area of the die (Fig. 9).

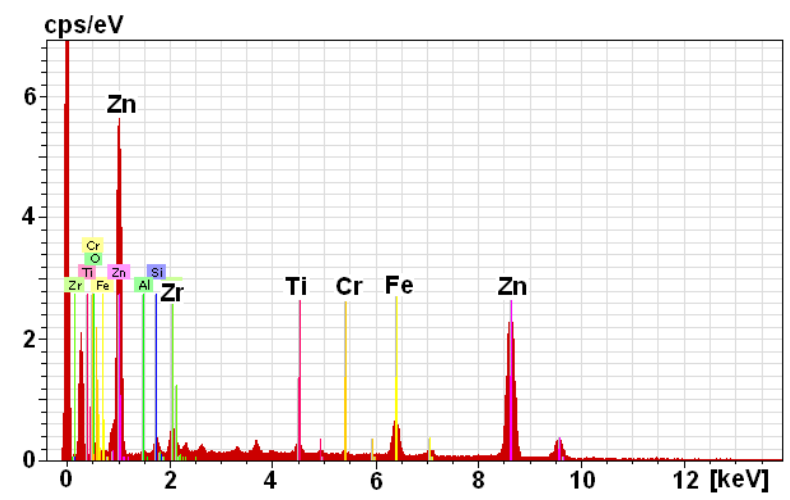

Fig. 11. EDX microanalysis in the area of ROD

An intense flow of material of clinched hot-dip galvanized steel sheets was present in the ROD area. According to characteristic marks after final machining, the grinding was performed in the $\mathrm{ROD}$ area in perpendicular direction to the main motion of the punch (Fig. 10). The original surface of $\mathrm{ZrN}$ coating in the ROD area has no surface defects.

In general, the surface roughness increases after deposition of PVD coatings. Clinching of hot-dip galvanized steel sheets without applying any lubricants in these extreme places can lead to the occurrence of zinc adhesion. Such adhesive pick-ups of zinc in the places of deterioration of ZrN coating were observed after 150 cycles of clinching of hot-dip galvanized steel sheets (Figs. 9 and 11).

The marks after machining were in the punch edge of radius $\mathrm{R} 0.5$, on the entire perimeter. The radius edge of $\mathrm{R} 0.5$ was not polished (Fig. 12).

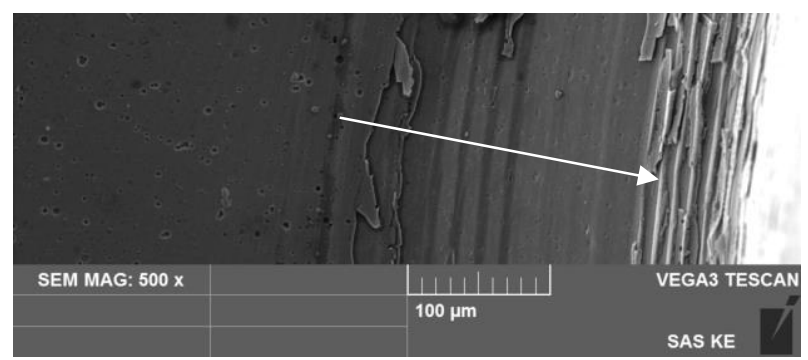

Fig. 12. Punch - surface in the edge of R0.5 and decohesion of $\mathrm{ZrN}$ coating

The tool was elastically deformed in each cycle of clinching of thin steel sheets. No changes in the tool shape were observed in the region of elastic deformation of the tool.

The compression test was used to experimentally determine maximum force of the punches $(\varnothing 3.6 \times 2.1 \mathrm{~mm}, \varnothing 5 \times 4 \mathrm{~mm})$ for work in the elastic range (Figs. 13, 14). Joining by clinching method is carried out at the connecting force $3-7 \mathrm{kN}$, i.e. tool is loaded in the elastic range. 


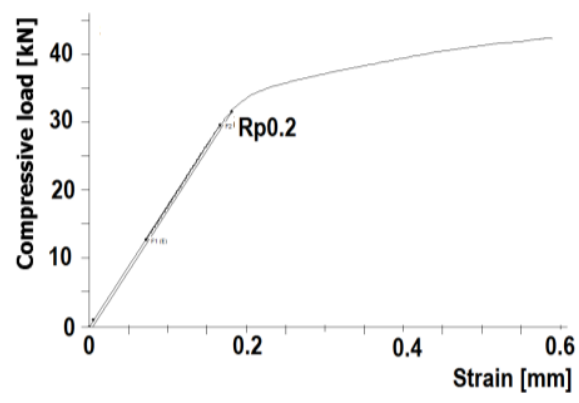

Fig. 13. Compression test of punch- $\varnothing 3.6 \times 2.1 \mathrm{~mm}$

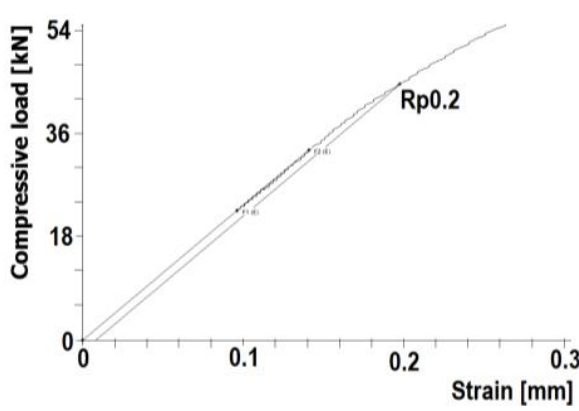

Fig. 14. Compression test of punch- $\varnothing 5 \times 4 \mathrm{~mm}$
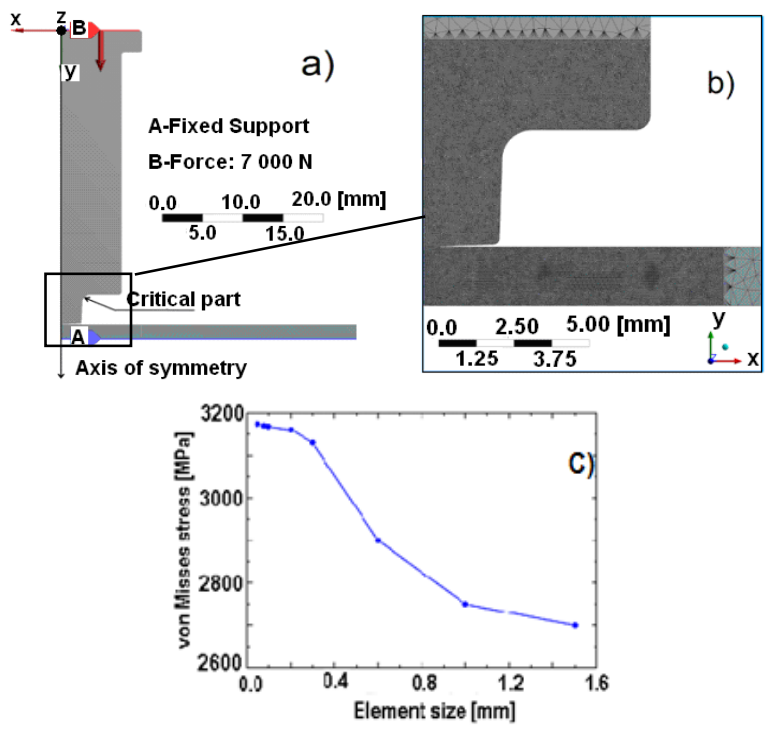

Fig. 15. Defined a) boundary conditions, b) finite element mesh, c) optimization of mesh

The level of elastic deformation in the tool is a function of material constants of tool material and roughness and treatment of the tool surface.

The qualitative information about changes in the extent of elastic deformation of the punch in the edge of R0.5 due to roughness increase in this area was obtained by FEM analysis. The mathematical modelling with finite element method (FEM) was used. The commercial software ANSYS version 15.0 was used for mathematical modelling. The task was solved as a contact of two objects: the tool (punch) penetrating the steel base using a simplified 2D axisymmetric model for saving computational time. The analysis consisted of two phases. In the first phase, the steel base was modelled as an elastic material, whereas in the second phase, an elastic perfectly plastic model was applied. The punch in both phases was as an ideally elastic material, since its hardness is significantly higher than hardness of the steel base.
Young's modulus $E$, Poisson's ratio $U$ in both phases were $E=$ $210 \mathrm{GPa}, \mathrm{v}=0.3$ and considering the calculation of elastic deformation of the punch, we assumed the yield strength of the steel base was $Y=2 \mathrm{GPa}$. The sheet thickness was $2 \mathrm{~mm}$. In the critical area (Fig. 12), the radius of curvature $R$ varied from 0 to 1.5 $\mathrm{mm}$. Boundary conditions and the finite element mesh are shown in Fig. 15.

In continuum mechanics, the relationship between stress and strain in uniaxial tension is supposed as:

$$
\begin{aligned}
& \sigma=E \cdot \varepsilon \Rightarrow \varepsilon \leq \frac{Y}{E} \\
& \sigma=K \cdot \varepsilon^{n} \Rightarrow \varepsilon \geq \frac{Y}{E}
\end{aligned}
$$

where $E$ is Young's modulus, $Y$ yield strength, $K$ hardening coefficient and $n$ is hardening exponent. The value of $n$ is from 0.1 to 0.5 for a wide range of materials. If value of $n=0$, the simulation model is considered as elastic-perfectly plastic. The coefficient $K$ for assurance of the continuity equals $Y(E / Y) n$. The equation (1) clearly shows that $E, Y$ and $K$ or $E, Y$ and $n$ are sufficient to describe the stress-strain relationship.

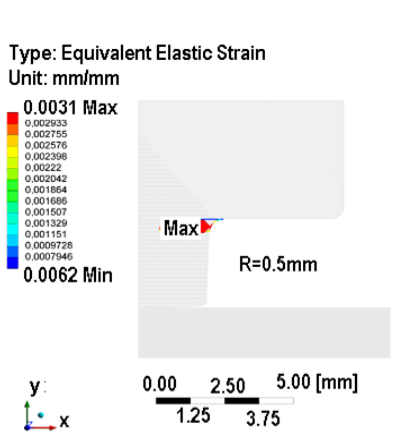

a)
Type: Equivalent Elastic Strain Unit: $\mathrm{mm} / \mathrm{mm}$
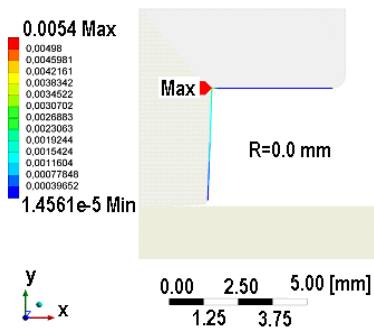

b)
Fig. 16. FEM model of critical edge with radius a) $R=0.5 \mathrm{~mm}$ and b) $R=0.0 \mathrm{~mm}$
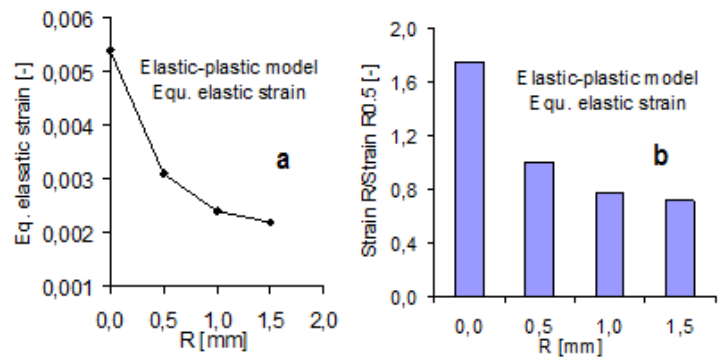

Fig. 17. Equivalent elastic strain vs. $R$

The FEM analysis of stress-strain state of the punch in the edge of radius $\mathrm{R} 0.5$ identified the area of maximum elastic deformation; and values of elastic deformation of the punch material in the edge of R0.5 were calculated. Information about the influence of technological notches, which remained in the punch after machining in the edge of R0.5, on the local value of elastic deformation of the punch was obtained by calculating the elastic deformation with values of $R=0.0 \mathrm{~mm}, R=0.5 \mathrm{~mm}, R=1.0 \mathrm{~mm}$ a $\mathrm{R}=1.5 \mathrm{~mm}$.

The sharp notches on the punch surface in the edge of R0.5 were approximated by the change of radius curvature in this area. The extent of elastic deformation in the surroundings of the notches can nearly double due to the polished surface of radius $\mathrm{R} 0.5$ (Figs. 16 and 17). 


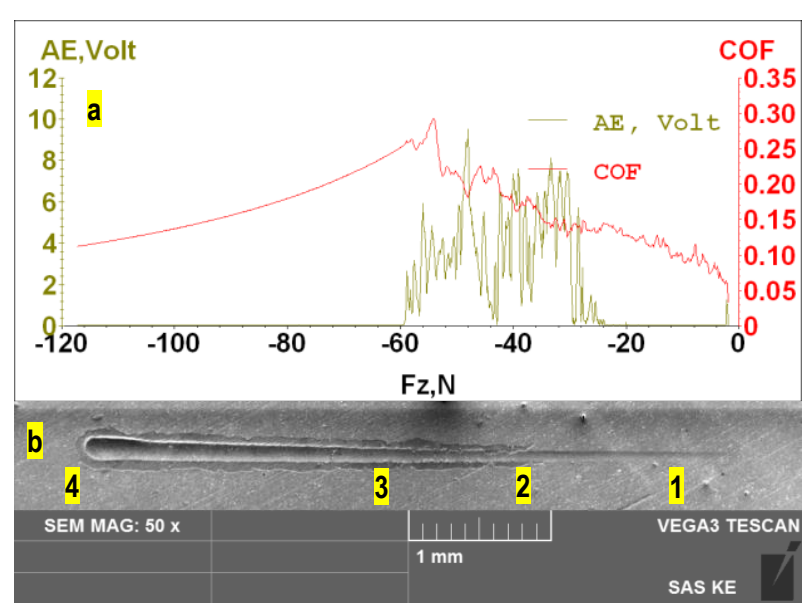

Fig. 18. ZrN, a) record AE-Fz, COF-Fz, b) scratch - disposition
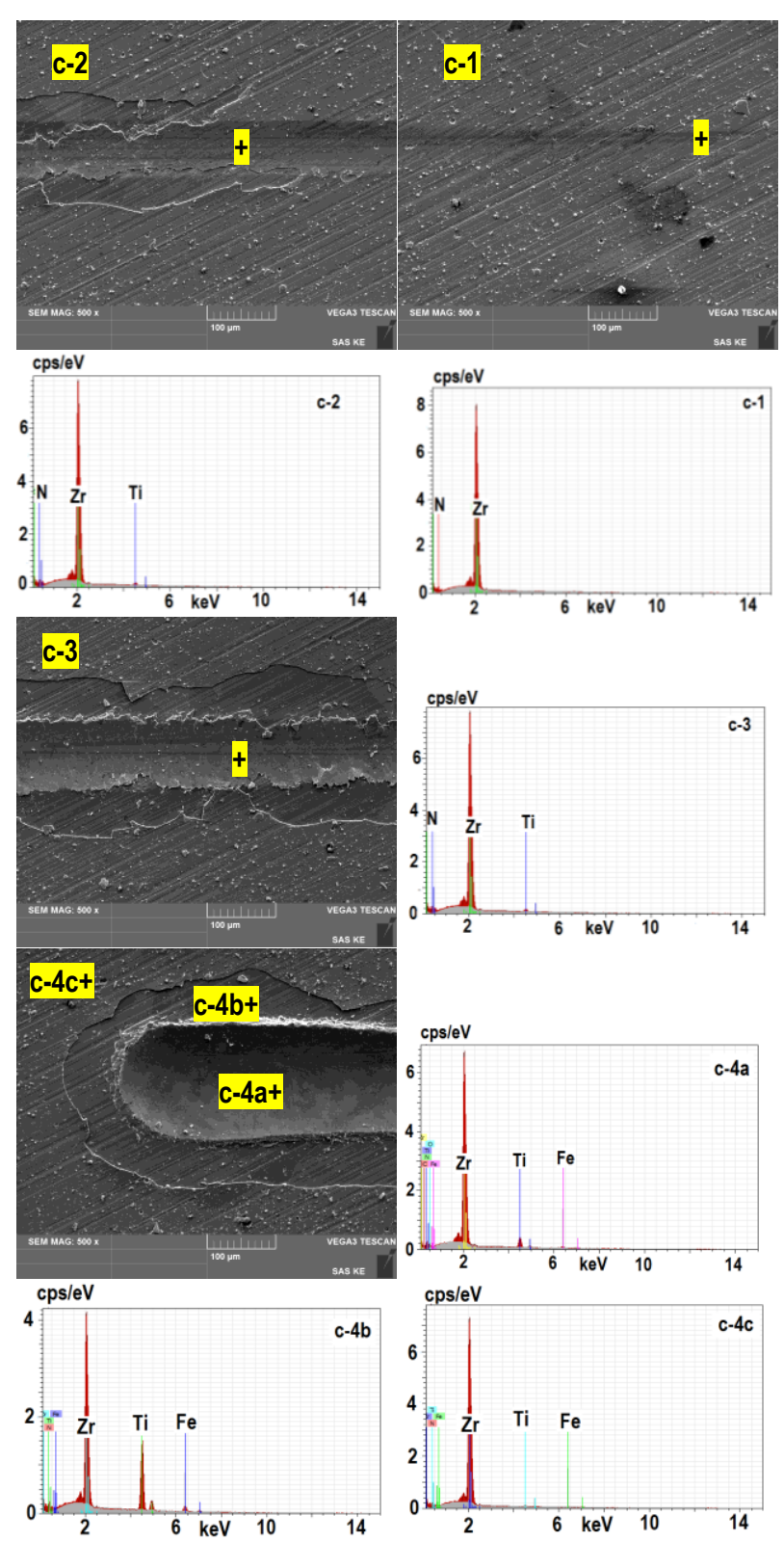

Fig. 19. ZrN - detail of the coating failure and qualitative EDX microanalysis in positions 1,2,3,4 from Fig. 18.
The information about adhesion of PVD coating of ZrN deposited on the base material $1.3343 / 55 \mathrm{HRc}$ was obtained by MicroScratch test with linear increase of normal force Fz. The value of PVD coating roughness according to ISO 4287 was Ra 0.30. The scratch test was performed on the appliance UMT/APEX MultiSpecimen using the diamond Rockwell indenter and with following test parameters: max. normal force $\mathrm{Fz}=-120 \mathrm{~N}$, speed of movement of the sample under indenter $=0.01 \mathrm{~mm} / \mathrm{s}$. Adhesive and cohesive properties of the coating system were evaluated by surface morphology after scratch test, graphic recording of acoustic emission signal (AE) and the coefficient of friction (COF) in dependence on the load magnitude Fz. The failures of surfaces of PVD coatings ZrN in the place of scratch test mark were observed by scanning electron microscope and evaluated according to ISO 20502:2005 (E) and ASTM C 1624-05 standards The ZrN coating in this test showed an increase in the acoustic emission at $20 \mathrm{~N}$, which can indicate a higher value of hardness of the surface layer and thereby its higher brittleness which usually leads to a significant increase in acoustic emission even if a small failure occurs (Fig. 18).

With the normal force exceeding $30 \mathrm{~N}$, there occurred largearea interfacial spallation in PVD coating. Qualitative EDX microanalysis of the scratch and its surroundings detected elements forming ZrN coating. Failure of ZrN coating during the scratch test occurred in PVD coating as interfacial spallation (Fig.19)

In case of the tool with PVD coating, the stresses that arose during the process of deposition of PVD coating on the surface significantly contributed to the internal stress. The qualitative information on stress or orientation of deformation in coating was obtained from X-ray phase analysis. The analysis of phase composition of ZrN coatings was performed by the method of grazing incidence $(\mathrm{GI})$ of $\mathrm{X}$-ray radiation measured with the angle of incidence $2^{\circ}$, in the interval from $20^{\circ}$ to $100^{\circ}$. The negative values of deformation of thin layer $\mathrm{ZrN}: \varepsilon=-0.013$ were measured in the PVD coating ZrN on the base material 1.3343, treated on 55HRc. The deformations were evaluated by $\mathrm{GI}$ measurements, so-called multiple hkl method. A negative value means that in all cases there was a compressed deformation; the layer was compressed in the plane parallel to the sample surface.

Any discontinuity in the shape or material non-uniformity is considered to be notch. Notches can be metallurgically-related (inclusions, blowholes, quenching, cracks etc.) or mechanicallyrelated (grooves, holes, threads, surface indentations etc.). It is not unusual that notches are present in the structural components. Grinding marks are typical form of notches in machined components. Hence surface topography and roughness are very important in terms of the resistance to nucleation and propagation of notch-related cracks. Notches do strongly affect the fatigue behaviour of ductile and also brittle materials, and are often related to crack initiation at the root of the notch because they serve as sites of stress concentration. At these sites, the local stress can increase to a much larger value than the nominal stress. Another important effect is the presence of the coating in the form of extremely thin layer which can be stressed either in tension or in compression. The nucleation and consequent forming and growth of surface cracks due to presence of the notches is similar in coated surfaces as is in components made of one material. In addition, residual stresses in the coating must be taken in to account. On the other hand, high-performance coating materials are considered to increase the crack-resistance and resulting fatigue strength. The combination of the stated phenomena can contribute to a large increase in stress above the nominal stress 
values which result in nucleation and further surface cracking leading to fracture. Moreover, stress concentrations are built up around discontinuities when the structure is loaded. Resulting cracking and material fracture are typical for brittle materials such as ceramic coatings. There are some special features in the cracking of a surface that is covered with a thin coating. Crack initiated in a thin coating propagates all the way down to the coating/substrate interface. The crack may change direction at the interface and can propagate along the coating/substrate interface, or it may propagate deeper into the substrate. Propagation of the cracks along the coating/substrate interface can be avoided when strong adhesion of the coating to substrate is observed. The crack growth in the lateral direction is related to interfacial coating delamination and both cracking and delamination result in the failure of coating. These phenomena result from stress concentration due to presence of notches acting as stress raisers, and they should be avoided because local stress level can exceed the strength of the material and can evolve further to fracture.

The degradation process of active parts of the tool (punch and cavity of a specially formed part of die) is a superposition of multiple degradation mechanisms. During the technical lifetime of the tools, degradation of the punch and the formed part of the die cavity can be controlled by multiple degradation mechanisms with time-varying intensity of the process. The degradation process of the active parts of the tool is normally localized in the area near the surface, where maximum stresses can exist at the level of macro and microstresses. The macrostresses are determined by total internal stress distribution in the tool during each cycle of clinching of thin steel sheets. The internal stresses in the tool at the level of microstresses are affected by the state of microstructure and substructure of the tool material as well as the value and the stress orientation.

\section{CONCLUSION}

$\mathrm{ZrN}$ coating in the edge of radius $\mathrm{R} 0.5$ of the punch was deteriorated by delamination of a part of the layer. Machining marks remained in the area of radius R0.5 due to imperfect polishing of this part, which caused the marks to behave as the technological notches during joining the hot-dip galvanized steel sheets. The $\mathrm{ZrN}$ coating was not deteriorated in the other areas of the punch surface. The increase in the roughness was in the edge of radius R0.5, with the local notch effect and the local increase in the elastic deformation in this area.

Compression stresses in $\mathrm{ZrN}$ coating parallel to the substrate surface were measured by the method of grazing incidence $(\mathrm{GI})$ of $\mathrm{X}$-ray radiation in the $\mathrm{ZrN}$ layer.

The process of degradation of the active parts of the joining tool - the punch and the cavity of the formed part of the die was a superposition of multiple degradation mechanisms.

Local adhesive pick-ups of zinc on the surface of ZrN coating were observed in the ROD area of the punch.

\section{REFERENCES}

1. Attar F., Johannesson T. (1996), Adhesion evaluation of thin ceramic coatings on tool steel using the scratch testing technique, Surface and Coatings Technology, 78, 87-102.

2. Chalker P.R., Bull S.J., Rickerby D.S. (1991), A review of the methods for the evaluation of coating-substrate adhesion, Materials Science and Engineering, A 140, 583-592.
3. Chen Ch., Zhao S., Cui M., Han X., Fan S., Ishida T. (2016), An experimental study on the compressing process for joining Al6061 sheets, Thin-Walled Structures, 108, 56-63.

4. Eshtayeh M.M., Hrairi M., Mohiuddin A.K.M. (2016), Clinching process for joining dissimilar materials: state of the art, The International Journal of Advanced Manufacturing Technology, 82, 179-195.

5. He X., Zhao L., Deng C., Xing B., Gu F., Ball A. (2015) Selfpiercing riveting of similar and dissimilar metal sheets of aluminum ally and copper alloy, Materials and Design, 65, 923-933.

6. ISO 20502(E): (2005), Fine ceramics (advanced ceramics, advanced technical ceramics) - Determination of adhesion of ceramic coatings by scratch testing.

7. Jiang T., Liu Z.X., Wang, P.C. (2015), Effect of aluminum prestraining on strength of clinched galvanized SAE1004 steel-toAA6111-T4 aluminum, Journal of Materials Processing Technology, 215, 193-204.

8. Kaščák L'., Spišák E., Mucha J. (2013), Clinchrivet as an alternative method to resistance spot welding, Acta Mechanica et Automatica, 7, 79-82.

9. Kaščák L', Spišák E., Mucha J. (2015), Mechanical joining of various materials by clinching method, Key Engineering Materials, 662, 205-208.

10. Kaščák L'., Spišák E., Spišáková E., Gajdoš I. (2015), Clinching an innovative trend in joining of combined materials in car body production, Materials Science Forum, 818, 217-220.

11. Lambiase F., Di llio A. (2015), Mechanical clinching of metalpolymer joints, Journal of Materials Processing Technology, 215, 12-19.

12. Lambiase F., Di llio A. (2016), Damage analysis in mechanical clinching: Experimental and numerical study, Journal of Materials Processing Technology, 230, 109-120.

13. Mucha J., Kaščák L'., Spišák E. (2011), Joining the car-body sheets using clinching process with various thickness and mechanical property arrangements, Archives of civil and mechanical engineering, $\mathrm{XI}$, 135-148.

14. Mucha J., Kaščák L'., Spišák E. (2013), The experimental analysis of forming and strength of clinch riveting sheet metal joint made of different materials, Advances in Mechanical Engineering, Vol. 2013, 1-11.

15. Mucha J., Witkowski, W. (2014), The clinching joints strength analysis in the aspects of changes in the forming technology and load conditions, Thin-Walled Structures, 82, 55-66.

16. Pulker H. K., Perry A. J., Berger R. (1981), Adhesion, Surface Technology, 14, 25 - 39.

17. Renzelli M., Mughal M.Z., Sebastiani M., Bemporad E. (2016), Design, fabrication and characterization of multilayer $\mathrm{Cr}-\mathrm{CrN}$ thin coatings with tailored residual stress profiles, Materials \& Design, $112,162-171$.

18. Rickerby D. S. (1988), A review of the methods for the measurement of coating-substrate adhesion, Surface and Coatings Technology, 36, $541-557$.

19. Śliwa A., Mikuła J., Gołombek K., Tański T., Kwaśny W., Bonek M., Brytan Z. (2016), Prediction of the properties of PVD/CVD coatings with the use of FEM analysis, Applied Surface Science, 388, 281-287.

20. Wang L., Wang Y., Zhang W.Q., Sun X.G., He J.Q., Pan Z.Y., Wang C.H. (2012), Finite element simulation of stress distribution and development in $8 Y S Z$ and double-ceramic-layer $\mathrm{La}_{2} \mathrm{Zr}_{2} \mathrm{O}_{7} / 8 \mathrm{YSZ}$ thermal barrier coatings during thermal shock, Applied Surface Science, 258, 3540-3551.

21. Witkowski, W. (2015), The shear strength of the round clinching joints formed by using extensible die, Advances in Science and Technology Research Journal, 9, 72-76.

Acknowledgments: The research was conducted under the research projects APVV-0682-11 and APVV-14-0834. 